\title{
Figure-background color differences and transfer of discrimination from objects to line drawings with pigeons
}

\author{
PATRICK A. CABE \\ National Institute of Environmental Health Sciences, Research Triangle Park, North Carolina 27709
}

and

\author{
MARGARET L. HEALEY \\ University of North Carolina, Chapel Hill, North Carolina 27514
}

\begin{abstract}
The effect of varying the color of the background behind two solid object discriminanda on transfer to line drawings was tested with pigeons. In Experiment 1, objects were placed in front of either a white or gray background for initial discrimination training, then, in transfer tests in extinction, the display background colors were either the same or switched, or the display was a line drawing of the objects. The switch from gray to white disrupted performance about as much as the switch to the line drawing. The switch from white to gray did not disrupt performance as much, but, again, no transfer to the line drawing was seen. In Experiment 2, the background color behind the objects was changed every day, the intention being to make background color irrelevant. No transfer to line drawings following this training was seen.
\end{abstract}

Objects in an environment are typically viewed against a chromatic and varied background. Pictures of environmental objects, however, generally suppress the background: The background is frequently intentionally out of focus in photographs or is depicted in paintings as indistinct shapes in muted tones.

Since line drawings typically reduce the background for objects to a colorless and featureless blank area, the color/contrast change between an object display and a line-drawing display might prove distracting and disruptive, especially to an untutored observer (a child, an individual from a culture not making pictures, or an animal subject). The widely known difficulties pictorially naive individuals have in interpreting line drawings (Miller, 1973) could perhaps be explained on this basis, although no apparent test of such a hypothesis is available.

Recent work (Cabe, 1976b; Cerella, 1977; Looney \& Cohen, 1974) suggests that laboratory pigeons fail to see line drawings as representations of objects. A possible explanation, at least for a failure of direct transfer from objects to line drawings (Cabe, 1976b), is that the change of background color/contrast distracts the pigeons and disrupts performance.

Portions of this work were performed while Patrick A. Cabe held a National Institute of Mental Health Postdoctoral Research Fellowship at the University of North Carolina at Chapel Hill. Reprint requests should be directed to: Patrick A. Cabe, Laboratory of Behavioral and Neurological Toxicology, National Institute of Environmental Health Sciences, Research Triangle Park, North Carolina 27709.
As a preliminary test of this hypothesis, two experiments were carried out. In the first, the effect of changing the background color behind two solid object discriminanda was compared to the effect of changing the solid object display to perspective line drawings of the objects. In the second, the effect on transfer to line drawings of multiple background colors during initial discrimination was tested.

\section{GENERAL METHOD}

\section{Subjects}

Nonnaive adult White Carneaux pigeons, maintained at $75 \%$ of free-feeding weight, were tested. None of the birds' histories, however, included discrimination or transfer.

\section{Apparatus}

A modified picnic hamper operant conditioning chamber was used. The response panel contained a single $2.5-\mathrm{cm}$ clear glass key (Cabe, 1976a), centered on the panel about $20 \mathrm{~cm}$ above the chamber floor. The pigeons could view the interior of a short tunnel (approximately $12.5 \times 12.5 \times 25 \mathrm{~cm}$ ) through the clear key. The end of the tunnel was a T-shaped panel, pivoted at the intersection of the $T$ such that a reversible motor and pulley-and-belt system could rotate alternative "ends" into and out of the tunnel. The stimulus displays were attached to the $T$ panel such that a successive discrimination could be programmed. The interior of the tunnel was painted navy gray and was illuminated by two $6-\mathrm{W}$ frosted bulbs mounted on the back of the response panel above and below the key. The tunnel lights provided the only illumination in the chamber. Low-level white noise was played into the chamber to mask apparatus sounds.

Mixed grain reinforcement was presented in a lighted hopper centered about $15 \mathrm{~cm}$ below the key.

The stimulus displays consisted of two white wooden blocks, 
one $5.7 \times 5.7 \times 1.9 \mathrm{~cm}$ thick and the other a triangular block $(5.7 \mathrm{~cm}$ base $\times 5.7 \mathrm{~cm}$ altitude $\times 1.9 \mathrm{~cm}$ thick). Each block was mounted on one face of the $T$ panel, free standing at a 45-deg angle (left side forward) to frontal parallel. Perspective line drawings of the two blocks (black ink on white card stock) were prepared and fastened to a second $\mathrm{T}$ panel.

Timing, control, and recording functions were implemented with standard electromechanical logic located in another room.

\section{Procedure}

The object displays were presented in daily 72-trial sessions following quasirandom schedules (Fellows, 1967). Each trial lasted $30 \mathrm{sec}$ and was preceded by a 10 -sec intertrial interval (ITI), during which the display could be changed. Pecks in the presence of the square block $\left(S^{D}\right)$ were reinforced (5-sec access to grain) on a variable-interval (VI) 1-min schedule; pecks in the presence of the triangular block $\left(S^{\Delta}\right)$ were never reinforced. Pecks during the ITI had no effect. Operation of the feeder did not extend the trial, but if the feeder was operating at the end of a $S^{D}$ trial, the succeeding ITI was postponed until the end of the feeder cycle.

The birds were trained on the object discrimination to a criterion of $75 \%$ (or better) of all responses to $\mathrm{S}^{\mathbf{D}}$ for 3 consecutive days. Transfer tests using altered displays were then administered following a sequence as used in discrimination training but under extinction. The original problem was then reinstated, and the birds were retrained to criterion and retested for transfer. This procedure was followed in both experiments until all the transfer tests had been completed.

\section{EXPERIMENT 1}

\section{Method}

Subjects. Six birds were tested.

Procedure. Three birds were trained on the object discrimination with a gray background, and the other three birds were trained with the same objects but with a white background. Each group was tested in three transfer conditions under extinction: (1) same background color (a control procedure), (2) switched background color (gray and white), and (3) line drawings of the objects. The order of transfer tests was balanced among the birds in each group using a Latin square.

\section{Results}

The results are shown in Table 1. Discrimination was clearly maintained when tested under extinction with the background color the same as in initial training (control). A switch in background color from gray to white disrupted performance about as much as presenta-

Table 1

Percent Total Responses (Total Responses) to $S^{D}$ Display

\begin{tabular}{ccccccc}
\hline & \multicolumn{5}{c}{ Transfer Condition } \\
\cline { 2 - 6 } Bird & Control & \multicolumn{3}{c}{ Switch } & \multicolumn{1}{c}{ Drawing } \\
\hline \multicolumn{6}{c}{ Gray Background in Training } \\
87 & 92.9 & $(1304)$ & 60.8 & $(665)$ & 46.8 & $(1611)$ \\
143 & 95.9 & $(1594)$ & 49.8 & $(785)$ & 55.3 & $(414)$ \\
170 & 95.0 & $(1192)$ & 66.4 & $(1016)$ & 56.5 & $(547)$ \\
Mean & 94.6 & \multicolumn{5}{c}{59.0} \\
\multicolumn{7}{c}{ White Background in Training } \\
144 & 82.5 & $(469)$ & 56.9 & $(541)$ & 55.9 & $(356)$ \\
145 & 92.6 & $(2182)$ & 88.4 & $(1281)$ & 43.6 & $(669)$ \\
171 & 83.7 & $(619)$ & 91.5 & $(1149)$ & 61.6 & $(1697)$ \\
Mean & 86.3 & \multicolumn{7}{c}{78.9} & & 53.7 \\
\hline
\end{tabular}

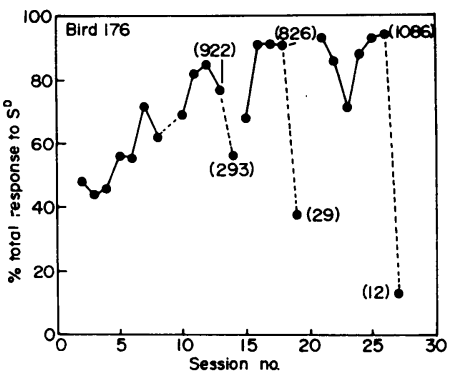

Figure 1. Learning/transfer curve for one pigeon trained on an object discrimination problem in which the background color was changed before every training session. Transfer to perspective line drawings was tested in Sessions 14, 19, and 27. Numbers in parentheses are total responses in sessions indicated.

tion of the line drawings; that is, on the average, discrimination performance dropped to chance levels. A switch from white to gray, however, had less effect, although, again, poor stimulus control by the line drawings was apparent.

Change in background color from the original object discrimination displays had an influence on transfer, but it made a difference what the original background color was.

Since one background color change had a large effect and the other a small effect on transfer to another object display (although no difference in transfer to the drawing displays could be seen), varied experience with the background colors might tend to make all background color changes nondisruptive. If figureground color/contrast is a major factor in object/linedrawing transfer, then making object-background color/contrast irrelevant through training might facilitate object/line-drawing transfer.

\section{EXPERIMENT 2}

\section{Method}

Subjects. Two birds were used. One, however, failed to learn the original discrimination. Transfer data are for the remaining bird.

Displays and Procedure. The same object displays and procedure as in Experiment 1 were used in the initial discrimination training, but pieces of colored construction paper of various hues and shades were taped to the panel as backgrounds for the objects. The same color paper was placed behind both objects, and the color was changed every day. Changing the color from day to day, it was thought, would make background color irrelevant and, presumably, facilitate transfer to line drawings if background color change had been a major factor working against transfer in other experiments. When the bird had reached criterion on the object discrimination, it was tested for transfer.

\section{Results}

Figure 1 shows the results of Experiment 2. It can be seen that performance is near chance at the first and second tests and below chance at the third test (although the very small number of responses renders the reliability of the percentage at the third suspect). 
Figure 1 gives no evidence of the pigeon's recognizing the objects in line drawings. It is also clear that the total number of responses in each transfer test is considerably less than the just-preceding training session, although the number of responses in the training sessions remained fairly stable.

\section{GENERAL DISCUSSION}

These two experiments replicate and extend earlier work (Cabe, 1976b). Pigeons do not appear to recognize free-standing objects represented in perspective line drawings, at least using the geometrical objects employed to date. The possibility that object-background color/contrast changes obviates transfer from objects to line drawings cannot be totally dismissed but, on the basis of the present data, does not seem to be a major factor working against transfer. Given that pigeons do seem quite capable of recognizing some objects, even rather arbitrary geometrical ones, in photographs (Cabe, 1976b), consistent failure to find transfer to line drawings may be an indication of a phylogenetic perceptual difference between avian and primate species (cf. Davenport, Rogers, \& Russell, 1975; Hochberg \& Brooks, 1962).

\section{REFERENCES}

CABE, P. A. An inexpensive glass response key. Behavior Research Methods \& Instrumentation, 1976, 8, 341. (a)

CABE, P. A. Transfer of discrimination from solid objects to pictures by pigeons: A test of theoretical models of picture perception. Perception \& Psychophysics, 1976, 19, 545-550. (b)

Cerella, J. Absence of perspective processing in the pigeon. Pattern Recognition, 1977, 9, 65-68.

Davenport, R. K., Rogers, C. M., \& Russell, I. S. Crossmodal perception in apes: Altered visual cues and delay. Neuropsychologia, 1975, 13, 229-235.

Fellows, B. J. Chance stimulus sequences for discrimination tasks. Psychological Bulletin, 1967, 67, 87-92.

HochbeRG, J., \& BRooks, V. Pictorial recognition as an unlearned ability: A study of one child's performance. American Journal of Psychology, 1962, 75, 624-628.

Looney, T. A., \& Cohen, P. S. Pictorial target control of schedule-induced attack in White Carneaux pigeons. Journal of the Experimental Analysis of Behavior, 1974, 21, 571-584.

MiLler, R. J. Cross-cultural research in the perception of pictorial materials. Psychological Bulletin, 1973, 80, 135-150.

(Received for publication November 2, 1978,) 